\title{
La historización de los conceptos teológicos en el pensamiento de Ignacio Ellacuría
}

\section{"The historicization of theological concepts in the thought of Ignacio Ellacuría"}

Randall Carrera U.

\begin{abstract}
Resumen
En esta investigación se realiza un análisis de lo que Ignacio Ellacuría comprende como historización. Se defiende la tesis de que la historización no se limita a la elucidación de ciertos criterios metodológicos, sino que es el eje que permite una nueva construcción y comprensión de los conceptos teológicos desde el horizonte particular de la realidad latinoamericana. El estudio parte de la explicitación de algunas categorías claves para comprender el pensamiento de Ellacuría, para luego profundizar en lo que el autor desarrolla sobre la historización; esto, a partir de la deconstrucción de sus implicaciones en la teología de la liberación, su aporte en la elaboración de algunos conceptos teológicos fundamentales y su papel desideologizador. Se ofrecen, además, algunas luces en lo relacionado a su aporte en la construcción de una metodología teológica latinoamericana.
\end{abstract}

Palabras claves: Ignacio Ellacuría, teología de la liberación, historización de la teología, método teológico

\begin{abstract}
This article explains Ignacio Ellacuría's understanding of historization. It is proposed that historization is not limited to the elucidation of methodological criteria but that it is the axis from which a new comprehension of methodological concepts derived from Latin America reality is allowed. The study begins with the explanation of some key categories to understanding Ellacuria's thoughts, then later digs deeper into what the author develops about historicization by deconstructing his implications about Liberation Theology, his contribution to the elaboration of some fundamental theological concepts and his role as ideological critique. Some additional insights are offered related to Ellacuria's contribution to the Latin American theological methodology.
\end{abstract}


Keywords: Ignacio Ellacuría, Theology of liberation, Historicization of theology, Theological method

\section{Introducción}

En esta investigación se realiza un abordaje del pensamiento teológico de Ignacio Ellacuría (1930-1989), filósofo y teólogo español- salvadoreño, desde uno de los principales ejes de su pensamiento: la historización de los conceptos. Esta es una de las temáticas en las que este pensador ofrece un aporte significativo al pensamiento latinoamericano, tanto en la dimensión filosófica como en la teológica.

Este análisis se encuentra delimitado a los aspectos de orden epistemológico, enfatiza los criterios que sustentan y justifican la opción por la historización en el ámbito estrictamente teológico, de esta manera, no se presenta un estudio específico de las categorías teológicas historizadas desarrolladas por Ellacuría; sino que se profundiza en los elementos centrales que constituyen la razón de ser de su método. Lo anterior, debido a dos criterios particulares: en primer lugar, hay que tomar en cuenta que la preocupación por desarrollar una teología liberadora para América Latina no es comprensible sin el eje historizador, pues el interés por desarrollar una teología desde las particulares propias de la realidad de la región se encuentra presente en, prácticamente, toda la obra de este autor. En un segundo momento, es fundamental tomar en cuenta que Ellacuría no ofrece explícitamente una metodología para historizar los conceptos teológicos, sino que desarrolla una profunda reflexión sobre la necesidad de contrastar con la historia y la realidad los datos propios de la elucubración teológica. Esta, en sus manos, se visualiza como un elemento dinámico, abierto a las vicisitudes históricas e interpelaciones propias del ser humano de hoy, y facilita la construcción de una teología a la altura de los tiempos ${ }^{1}$. Sin embargo, en su propuesta sobre el ser de la teología de la liberación y su respectiva metodología emergen elementos sumamente relacionados con esta

1 En el ámbito propiamente filosófico Ellacuría también mantiene la preocupación por la historización de los conceptos, principalmente en lo relacionado a la desideologización de la realidad, con la diferencia de que en tres de sus escritos titulados "La historización del concepto de propiedad privada como principio de desideologización (1976); "Historización del bien común y los derechos humanos en una sociedad dividida (1978) e "Historización de los derechos humanos desde los pueblos oprimidos y las mayoría populares (1989), ofrece luces metodológicas para abordar temáticas concretas, tales como los derechos humanos o la propiedad privada. Además, en el curso dictado en la Universidad Centroamericana Simeón Cañas, titulado "ideología e inteligencia" (1982) expone el tema en íntima relación con la inteligencia. Por la relación particular que en este autor gozan la teología y la filosofía es posible trasladar algunos de estos aportes a la reflexión teológica, tal como se plantea en el apartado final de esta investigación. 
temática, los cuales son asumidos en esta investigación como un criterio fundamental para su comprensión.

La investigación se estructura en tres apartados concretos. El primero ofrece una ubicación sobre algunas categorías necesarias para comprender el pensamiento teológico de Ellacuría, tales como su vínculo con la teoría de la inteligencia de Zubiri (1898-1983) y la explicitación de las nociones de historia y realidad, nociones tomadas también de la filosofía de su maestro, pero llevadas a una dimensión teológica liberadora, completamente novedosa. El segundo, por su parte, aborda específicamente la propuesta historizadora de Ellacuría, estructurándose en cuatro secciones: un análisis del contraste existente entre la teología tradicional y la teología de la liberación latinoamericana, desde la óptica de la historización; un breve abordaje sobre como la historización puede iluminar algunos conceptos teológicos fundamentales, un estudio sobre el aporte desideologizador de la historización, para culminar con algunas reflexiones teológicas. Finalmente, en el último apartado se ofrecen algunas conclusiones y valoraciones sobre el tema.

\section{Nociones previas fundamentales}

Para comprender el pensamiento teológico de Ignacio Ellacuría, es necesario analizar algunas nociones fundamentales, las cuales son desarrolladas a partir del pensamiento de Zubiri. En lo relacionado con la historización de los conceptos, cobran importancia tres categorías: la inteligencia sentiente, la historia y la realidad, las cuales se encuentran mutuamente relacionadas ${ }^{2}$.

\subsection{El papel de la inteligencia}

Ellacuría asimila la noción de inteligencia sentiente desarrollada por Zubiri, la cual no debe analizarse en los términos tradicionales, pues han dado lugar a todo tipo de reduccionismos e idealismos, planteando una clara separación entre el sujeto y el objeto del conocimiento, pero principalmente entre el inteligir y el sentir ${ }^{3}$.

Tanto para Zubiri como para Ellacuría, el inteligir es un modo de sentir y el sentir un modo de inteligir, ambos se encuentran unidos al formar parte de una misma estructura, no se trata

2 Para la debida comprensión de estos planteamientos es importante tomar en cuenta, tal como lo apunta Manuel Domínguez en su artículo “Aproximaciones al concepto de praxis en Ignacio Ellacuría" (Universitas Philosophica, 21, 1993, 46.) que "el estilo filosófico de Ellacuría es difícil. Sacrificó la fluidez y elegancia del lenguaje a la precisión y el rigor de los conceptos. Dado su empeño en lograr una rigurosa transposición conceptual de las complejidades estructurales del mundo real, sus expresiones resultaban en ocasiones recargadas e incluso tortuosas". Por ello, la comprensión de su pensamiento no es sencilla para quien no posee formación en la metafísica zubiriana.

3 Cf. Xavier Zubiri, Inteligencia sentiente. Inteligencia y realidad (Madrid: Alianza Editorial- Fundación X. Zubiri, 2011), 17-40. 
de nociones opuestas, como tradicionalmente se ha pretendido demostrar en la epistemología clásica, ya que "Todo lo biológico en el hombre es intelectivo, como todo lo intelectivo es en el hombre biológico"4, esta mutua relación abre un nuevo panorama para la teoría del conocimiento, ya que ambos se toman como componentes de una misma estructura $^{5}$. Para ambos autores esta visión de la inteligencia sentiente es la que permite establecer una clara diferencia entre los seres humanos y los animales, pues ambos se encuentran insertos en un medio y abiertos a la sensibilidad, con la clara diferencia de que el animal se enfrenta diariamente a estímulos, es decir, se desarrolla en el medio a través del ámbito de la estimulación.

Mientras que el ser humano, por su inteligencia sentiente, tiene que encontrar una forma diferente de habituarse a las cosas, de enfrentarse a ellas, de este modo lo que para el animal es estímulo, para la persona son realidades. Como bien lo ha expresado Héctor Samour, para Ellacuría "la sensibilidad humana, a diferencia de la pura sensibilidad animal, la alteridad aprehendida no queda actualizada como mero estímulo, sino como real:

4 Ignacio Ellacuría, "Ideología e inteligencia", en Cursos universitarios (El Salvador: UCA Editores, 2009), 25.

5 Cf. Ignacio Ellacuría, "Superación del reduccionismo idealista", en Escritos filosóficos III (El Salvador: UCA Editores, 2001), 404-26. el hombre siente impresivamente la realidad de lo real"'.

Quiere decir que la inteligencia, desde la perspectiva de estos autores, no se limita a transmitir simples contenidos, sino que facilita la aprehensión de la realidad; es decir, una marcha intelectiva hacia la realidad de las cosas, por lo que es válido afirmar que lo que se aprende como estímulo se agota en la estimulación misma, en cambio cuando la cosa es aprehendida por la inteligencia como realidad, permite acceder a su índole real ${ }^{7}$.

Como se analizará posteriormente, esta visión incidirá, de manera profunda, en la teología de Ellacuría, al ofrecer la base para generar nuevos planteamientos, más allá de los esbozados desde una epistemología tradicional.

\subsection{Realidad e historia}

Para Ellacuría, Zubiri no solamente ofreció un aporte fundamental en materia de epistemología, al elaborar una nueva teoría de la inteligencia, Desde su perspectiva, el filósofo vasco va más allá, al cargar la realidad de contenido metafísico. Pues no basta con el estudio del ser, ya que este se encuentra instaurado en la realidad y es

6 Héctor Samour, Voluntad de liberación. La filosofia de Ignacio Ellacuría (E1 Salvador: UCA Editores, 2006), 55.

7 Cf. Ignacio Ellacuría, "La historicidad del hombre en Xavier Zubiri”, en Escritos filosóficos II (El Salvador: UCA Editores, 2007), 218. 
ella la que realmente permite conocer las cosas.

Se puede afirmar que para Ellacuría la realidad posee una primariedad epistemológica, pues es en el acto de inteligir donde se muestra lo real de las $\operatorname{cosas}^{8}$, por lo cual la realidad, temática fundamental del pensamiento zubiriano se convierte en un eje transversal del pensamiento teológico, pues "en esa realidad intramundana, y precisamente en sus aspectos de historia, es tal vez donde, de alguna manera, sin confundirse con ella, está presente la realidad de Dios" .

De igual manera, la posición de Zubiri con respecto a la historia será fundamental en el andamiaje de la obra ellacuriana, pues se considera como un dinamismo de posibilitación, ya que es en esta donde la realidad se manifiesta de manera más plena y ofrece al ser humano, concebido como animal de realidades, todo un abanico de posibles realidades para su apropiación. Es decir, es en la historia humana donde se realiza así mismo dando capacidad a sus propias posibilidades ${ }^{10}$.

8 Cf. Ignacio Ellacuría, "Principialidad de la esencia en Xavier Zubiri”, en Escritos Filosóficos I (El Salvador: UCA Editores, 2007), 149-76.

9 Ignacio Ellacuría, "El desafío cristiano de la teología de la liberación”, en Escritos Teológicos I (El Salvador: UCA Editores, 2000), 23.

10 Cf. Ignacio Ellacuría, "El esquema general de la antropología zubiriana", en Escritos filosóficos II (El Salvador: UCA Editores, 2007), 348-56.
Esto lo lleva a expresar que la vida humana es histórica, fuera de ella no hay acceso a la realidad, "como realidad personal, es principio necesario de que su vida personal sea histórica, en la actualización, por decisión de las posibilidades que le son ofrecidas o que el crea" ${ }^{11}$. Por tanto, es en la historia donde se unen inteligencia y realidad, lo que la convierte en el lugar último de revelación de la verdad ${ }^{12}$.

Estas tesis permiten comprender la razón por la cual Ellacuría desarrolla una categoría conceptual que comprende los elementos, tanto de la realidad como de la historia. La realidad histórica, la cual reúne todas las formas de realidad: material, biológica, personal y social $^{13}$. Como apunta José M. Mardones, la realidad histórica es la totalidad de la realidad, donde se manifiestan las máximas posibilidades de lo real, es el lugar donde la realidad da de sí, es el ámbito en el que se manifiestan plenamente los dinamismos de la realidad ${ }^{14}$.

11 Ignacio Ellacuría, "La historicidad del hombre en Xavier Zubiri”, en Escritos filosóficos II (El Salvador: UCA Editores, 2007), 238.

12 Cf. Ignacio Ellacuría, Filosofía de la realidad histórica (Madrid: Editorial Trotta- Fundación X. Zubiri, 1991), 473-4.

13 Cf. Ignacio Ellacuría, "El objeto de la filosofía", en Escritos políticos I (El Salvador: UCA Editores, 2005), 63-92; véase también su obra fundamental Filosofia de la realidad histórica (Madrid: Editorial Trotta, 1991), en la que desarrolla a profundidad cada uno de sus elementos.

14 Cf. José M. Mardones, "La historización de los conceptos teológicos", en La pasión por la libertad. Homenaje a Ignacio Ellacuría (Navarra: Editorial Verbo Divino), 199. 
A lo largo de esta investigación, se evidenciará el uso que Ellacuría realiza de estas categorías en la construcción de su pensamiento teológico, particularmente en lo relacionado con la historización.

\section{La historización de los conceptos teológicos}

El tema de la historización es recurrente en toda la obra teológica de Ellacuría, por lo que se inicia su estudio analizando el contraste existente entre la teología tradicional y la teología de la liberación. Para luego dar paso a su explicitación en algunos conceptos teológicos fundamentales y su aporte como elemento desideologizador. Se finaliza con algunas luces en torno a su aporte en la reflexión teológica latinoamericana contemporánea.

\subsection{La historización como factor de confrontación entre la teología tradicional y la teología de la liberación}

Como teólogo de la liberación Ellacuría desarrolla su pensamiento a partir de una premisa fundamental: la teología tradicional ha sido incapaz de realizar un diálogo abierto con el entorno en que se desarrolla, su deseo de universalidad la ha llevado a una dimensión abstracta, completamente ajena a la realidad cotidiana, y la ha convertido en un saber meramente teórico, centrado sobre realidades inmutables, completamente ajenas a la historia ${ }^{15}$.

Esta forma tradicional de hacer teología se ha realizado desde una realidad determinada, la europea, la cual es limitada, pues: "La historia de la teología enseña que la situación histórica posibilita y a la par limita la realización de una teología viva" ${ }^{\prime \prime}$, es decir, al tener su génesis en un contexto diferente al latinoamericano, la teología ha desarrollado toda una serie de elementos necesarios para su construcción como una disciplina formal, debidamente estructurada y con criterios claramente establecidos, con el riesgo de verse incapaz de salir de los esquemas con los que ha sido diseñada a lo largo de los tiempos.

De esta manera, "La historización de la fe, tal como ha llegado al mundo, a través de la civilización occidental, a pesar incluso de sus universales, es una limitación de la fe cristiana"17. Por tanto, no es casualidad que las teorías teológicas, tal como han sido desarrolladas en Occidente, sean ajenas a lo que

15 Cf. Ignacio Ellacuría, "La teología como momento ideológico de la praxis eclesial", en Escritos teológicos I (El Salvador: UCA Editores, 2000), 164.

16 Ignacio Ellacuría, "Tesis sobre la posibilidad, necesidad y sentido de una teología latinoamericana", en Escritos teológicos I (El Salvador: UCA Editores, 2000), 273.

17 Ellacuría, "El desafío cristiano...", 31. 
experimentan los pueblos latinoamericanos; para Ellacuría, por el contrario "la revelación misma es histórica en su misma estructura, de modo que no puede tener un único sentido unívoco, para situaciones realmente distintas" 18 , por lo que el dato teológico debe verse interpelado por la realidad y la historia.

Desde su posición, se plantea la superación de los límites que a lo largo de la historia han impedido el desarrollo de una verdadera teología creativa en América Latina, pues la oposición de la teología europea al aporte de la historicidad, es decir, de las circunstancias particulares experimentadas por las mayorías oprimidas, la han convertido, en no pocas ocasiones, en un instrumento ineficiente en el proyecto salvífico.

Ellacuría contrasta este vacío tradicional de la teología europea con la riqueza presente en la teología de la liberación, la cual se multiplica con su diálogo e interpelación con la realidad, por medio de un proceso de historización de sus contenidos fundamentales. Por ello considera que "[...] la teología de la liberación debe orientarse a la liberación histórica trascendente, de modo que esa liberación no se dé sólo en la propia práctica teórica que es la teología, sino en la realidad de los

18 Ignacio Ellacuría, "La teología como momento ideológico de la praxis eclesial", en Escritos teológicos I (El Salvador: UCA Editores, 2000), 166. hechos, tanto en el aspecto histórico como en el trascendente" 19 .

Esto significa que para Ellacuría la teología no puede limitarse a la elucubración de nociones meramente teóricas, ya que se construye "sin perder su valor trascendente y metahistórico, se historiza para poder seguir viviendo $\mathrm{y}$ luchando"20. Por ello no hay espacio en este pensamiento teológico para ningún tipo de reduccionismo, pues no se limita a un abordaje meramente histórico, sino que más bien lo histórico es considerado un elemento que interpela al dato teológico. Esta historización se realiza con el objetivo de construir la liberación, por ello: "la teología de la liberación impulsa a situarse real e intencionadamente en la situación y perspectiva de las mayorías populares, para entender, interpretar y transformar la realidad, así como para vivir la plenitud del evangelio, tanto en lo personal como comunitariamente" 21 .

De esta manera, la historización permite contribuir a los diversos procesos de liberación necesarios en una determinada praxis histórica con miras a facilitar verdaderas transformaciones en dichas situaciones ${ }^{22}$.

19 Ignacio Ellacuría, "Relación teoría y praxis en la teología de la liberación”, en Escritos teológicos I (El Salvador: UCA Editores, 2000), 237.

20 Ellacuría, "El desafío cristiano...", 28.

21 Ignacio Ellacuría, "El desafío cristiano de la teología de la liberación", en Escritos teológicos I (El Salvador: UCA Editores, 2000), 26.

22 Cf. Ignacio Ellacuría, "Tesis sobre la posibilidad, necesidad y sentido de una teología 


\subsection{Revelación, salvación y reino, en el horizonte de la historización}

En el esfuerzo de Ellacuría por historiar la teología, las nociones de revelación, salvación y el reino cobran una importancia vital, como conceptos fuerza para orientar el desarrollo de un pensamiento teológico latinoamericano realmente encarnado.

Sin intentar realizar un análisis de fondo en torno a las nociones de revelación, salvación y reino, es necesario partir del presupuesto de que para Ellacuría "La revelación y la salvación cristiana no sólo se han dado históricamente, sino que constituyen una historia de la salvación. Por ello no hay posibilidad de revelación, sino en lo histórico y para quien tenga historia" ${ }^{23}$, pues ambos conceptos implican una realización progresiva en la historia. Por esto, deben encarnarse en la realidad de América Latina con el objetivo de abrir paso a verdaderos procesos de liberación, ya que solo pueden comprenderse en el marco de un proceso histórico, en el que los aspectos de naturaleza política cobran vital importancia.

Desde esta perspectiva, es evidente que el reino se comprende como uno de los contenidos fundamentales y

latinoamericana", en Escritos teológicos I (El Salvador: UCA Editores, 2000), 276.

23 Ignacio Ellacuría, "El desafío cristiano...", 22. orientadores de la teología de la liberación, pues si "el objeto fundamental de la misión de Jesús fue el reino de Dios, debe serlo también de la praxis eclesial y del momento ideológico de esa praxis" ${ }^{24}$. Razón por la cual es fundamental preguntarse cómo comprendió Jesús el reino y cómo debe comprenderse hoy, desde las coordenadas propias de la realidad latinoamericana, con miras a encontrar la praxis adecuada para su concreción en la historia.

Por tanto, al estudiar la teología es inconcebible partir de una noción genérica, por lo que es necesario el estudio de sus exigencias en una determinada situación histórica, con miras a aprehender lo que realmente es vital, de esta manera, afirma Ellacuría, "no se pierde así nada de la denominada trascendencia, aunque tampoco se conserva necesariamente todo lo que sobre esa trascendencia divina han elucubrado los hombres" ${ }^{\prime 25}$. Con esto, lo que se busca es recalcar que el reino de Dios apela a la presencia de Dios en la historia, al ser humano concreto, sin espacio para los dualismos, por eso el objeto de la teología es el reino como concepto estructuralmente histórico, una realidad dinámica en constante realización.

24 Ignacio Ellacuría, "La teología como momento ideológico de la praxis eclesial”, en Escritos teológicos I (El Salvador: UCA Editores, 2000), 175.

25 Ignacio Ellacuría, "La teología como momento ideológico de la praxis eclesial”, en Escritos teológicos I (El Salvador: UCA Editores, 2000), 177. 
Todo lo anterior le facilita a Ellacuría afirmar que la presentación, desde una perspectiva histórica, del reino, debe llevar a su comprensión como utopía, pero no como una noción distante, sino como una meta cuyo camino se traza por medio del profetismo, de manera que "No se conoce de antemano y menos a priori cuál puede ser la concreción histórica de la utopía cristiana y sólo una utopía cristiana concreta es operativa para la historización del reino de Dios" ${ }^{\prime 26}$.

\subsection{Historización versus ideologización}

La historización no solo colabora en la construcción y comprensión de los conceptos fundamentales de la teología, sino también en lo que Ellacuría denomina desideologización. Para entender esta aseveración es necesario, primero, realixar una referencia a lo que el autor comprende como ideología e ideologización.

En el pensamiento de Ellacuría, la ideología es más que un conjunto de ideas que conforman el pensamiento de un individuo o grupos sociales. En su curso sobre Ideología e inteligencia dictado en 1982, luego de analizar la ideología desde los planteamientos de

26 Ignacio Ellacuría, "Utopía y profetismo", en Mysterium Liberationis: Conceptos fundamentales de la teología de la liberación, dirigido por Ignacio Ellacuría y Jon Sobrino (El Salvador: UCA Editores, 2008), 394.
Platón. Bacon, Marx y Engels, esboza las siguientes tesis personales ${ }^{27}$.

Existe una necesidad histórica en los grupos sociales de construir un conjunto sistemático de criterios que permitan interpretar y valorar las relaciones humanas, tanto en el plano individual como en el social; dicho bagaje de representaciones, apreciaciones, normas o intereses, que incluyen un elemento de aceptación por parte de los miembros del colectivo social, es denominado ideología.

De esta forma, la ideología se considera como un elemento constitutivo, tanto de la inteligencia humana, como del convivir social, cuya valoración sería positiva. El problema radica cuando se da, en el conjunto social o político, lo que Ellacuría denomina ideologización, la cual acaece, en el momento en que uno de los elementos que conforman la instancia ideológica predomina por encima de los demás, ocultando la realidad, favoreciendo intereses creados y justificando situaciones que se alejan del bien común.

\section{Ellacuría plantea este ejemplo}

(...) cuando una sociedad está injustamente estructurada, sobre todo en el campo de lo económico [...] surgirá necesariamente una ideología justificadora de esa situación,

27 Cf. Ignacio Ellacuría, "Ideología e inteligencia", en Escritos teológicos I (El Salvador: UCA Editores, 2008), 327-78. 
que buscará mantenerla e impedir su rompimiento. En este caso la ideología toma ya un sentido peyorativo en el doble sentido de dar una representación desfigurada de la realidad y de dar una justificación desfigurada de la misma ${ }^{28}$.

Significa que la ideología utilizada correctamente colabora en la organización de la sociedad, pero su uso negativo como principio de ideologización colabora a un falseamiento de la realidad y a la justificación de situaciones y estructuras injustas, presentando un enmascaramiento de la realidad. Luchar contra esta falsedad ideológica es un objetivo propio tanto de la filosofía ${ }^{29}$ como de la teología.

Ellacuría es consciente que la ideologización no afecta solamente los discursos políticos o económicos presentes en la sociedad, sino que también puede estar presente en la dimensión teológica, cuando muchos conceptos son alejados de la realidad, con la intención de justificar situaciones de poder ajenas al plan de salvación. En esta línea afirma que pueden darse teorías

28 Ignacio Ellacuría, "Ideología e inteligencia", en Escritos teológicos I (El Salvador: UCA Editores, 2008), 370.

29 En el ámbito filosófico Ellacuría propone que la filosofía debe ser un elemento de desideologización, por medio del cumplimiento de su función crítica y creadora. Confróntese principalmente sus obras "Función liberadora de la filosofía", en Escritos políticos I (El Salvador: UCA Editores, 2005), 93-122 e Ignacio Ellacuría, “¿Filosofía para qué?”, en Escritos filosóficos III (El Salvador: UCA Editores), 115-32. teológicas completamente irrelevantes para situaciones teológicas concretas, principalmente las relacionadas con la situación de pobreza y marginación de Latinoamérica.

Su posición crítica en este tema es acuciosa y profunda, y explicita la necesidad de "Sospechar que no hay un producto teológico histórico y políticamente neutro. El teólogo, por tanto, debe preguntarse a quienes y a qué conducta favorecen sus reflexiones o quienes se hallan a gusto con ellas" ${ }^{\prime 30}$. Es decir, que en momentos concretos el pensamiento eclesial y la jerarquía no han privilegiado la liberación integral, sino que han favorecido a ciertas instancias políticas y económicas, por medio de una teología pasiva, que llama a la permisividad y con poco compromiso con la realidad histórica de las mayorías oprimidas. Apunta Ellacuría: "Esa Iglesia institucional así entendida no es garantía de la verdad teológica, sino más bien principio de ideologización" ${ }^{\prime 31}$.

Esta ideologización de la teología puede ser subsanada a partir de un método teológico enraizado en la realidad latinoamericana, donde la historización

30 Ignacio Ellacuría, "La teología como momento ideológico de la praxis", en Escritos teológicos I (El Salvador: UCA Editores, 2008), 167.

31 Ignacio Ellacuría, "El método en la teología latinoamericana", en Escritos teológicos I (El Salvador: UCA Editores, 2008), 233. 
es un principio fundamental, tal como se detalla a continuación.

\subsection{Historización y método teológico latinoamericano}

En este apartado no se pretenden desarrollar a fondo los elementos que conforman el método teológico latinoamericano, sino analizar algunos de los aportes que la historización ofrece a la reflexión teológica latinoamericana actual, para ello se parte de un abordaje de los principios epistemológicos propios de la teoría de la inteligencia zubiriana, para dar paso a una propuesta de aplicación del método de historización de los conceptos.

Como punto de partida hay que tomar en cuenta que para Ellacuría el método teológico latinoamericano no se formula con la intención de garantizar la ortodoxia de las verdades teológicas, sino que, desde su visión, lo más importante radica en que los contenidos teológicos se desarrollen en relación directa con la historia, en sintonía con un claro objetivo desideologizador ${ }^{32}$. Por tanto,

(...) el método histórico no se reduce a un recorrido histórico del que se busca críticamente su significatividad, sino que debe adecuarse a lo que es la historia como proceso real y englobante de toda la realidad humana, personal y estructuralmente considerada. Historia no es

32 Ellacuría, "El método...", 233. primariamente autenticidad crítica, sino proceso de realización $\mathrm{y}$, en definitiva, proceso de liberación ${ }^{33}$.

\subsubsection{Teología latinoamericana, teoría de la inteligencia e historización}

Tal como se mencionó, la teología tradicional se caracteriza por su deseo de universalidad e inmutabilidad, aspecto que viene en detrimento de la formulación ahistórica de sus contenidos. Por el contrario, la teología propuesta desde América Latina, por Ellacuría, se caracteriza por poseer un sustento epistemológico distinto, tomado de la teoría de inteligencia de Zubiri y aplicado, de manera particular, a la realidad latinoamericana ${ }^{34}$.

La inteligencia humana es sentiente, por ello, siempre realiza una función biológica: "Lo que hace la inteligencia, por muy formalmente irreductible que sea, lo hace en unidad primaria con todas las demás notas de la realidad humana" ${ }^{35}$. Quiere decir, que

33 Ignacio Ellacuría, "Hacia una fundamentación del método teológico latinoamericano", en Escritos teológicos I (El Salvador: UCA Editores, 2000), 199.

34 En el apartado 2.1. se analizó a nivel general el papel de la teoría de la inteligencia en la obra de Ellacuría, en este apartado se pretende demostrar su impronta en la obra teológica, particularmente en relacionado con el ámbito metodológico.

35 Ignacio Ellacuría, "Hacia una fundamentación del método teológico latinoamericano", en Estudios teológicos I (El Salvador: UCA Editores, 2008), 206. 
desde la realidad física, el ser humano realiza su intelección, fuera de ella no hay proceso racional, desde ahí conoce $\mathrm{y}$ entiende. Esto permite comprender por qué, para Ellacuría, la realidad es tan importante en la teología, pues la persona, desde su inteligencia, aprehende la realidad y se enfrenta con ella, ya que "En relación con su primaria referencia a la vida, lo específico y formal de la inteligencia es hacer que el hombre se enfrente consigo mismo y con las demás cosas en tanto que reales" ${ }^{\prime 36}$.

Estos principios, aplicados a la teología latinoamericana, permiten visualizar la realidad como algo intrínseco al ser humano, como el espacio en el que se aprehende y descubre la verdad, por ello el compromiso con su transformación y la denuncia ante todo tipo de injusticia estructural presente en ella. Por lo tanto, el ser humano se encuentra llamado a enfrentarse con la realidad en una triple dimensión, a saber:

Hacerse cargo de la realidad, esto significa estar en la realidad de las cosas, y no en una simple idea de ellas o en su mero sentido, todo lo contrario, a una inercia, implica estar entre las cosas y sus mediaciones materiales. También le compete cargar con la realidad, Ellacuría señala el carácter ético de la inteligencia, el cual no es poseído por el hombre para evadir los compromisos, sino para cargar sobre sí lo que realmente son las cosas y sus

36 Ellacuría, "Hacia una fundamentación...", 208. exigencias. Finalmente le corresponde encargarse de la realidad, donde se visualiza el carácter práxico de la inteligencia que debe hacerse cargo de un hacer real ${ }^{37}$.

De esta manera es evidente que la inteligencia humana es siempre histórica, es algo que le pertenece a su estructura, esto implica un carácter histórico de los mismos contenidos teológicos. Desde su perspectiva, existen tres aspectos claves de la historicidad de la inteligencia, sumamente influyentes en la teología.

Primero: todo la inteligencia está condicionada por el mundo histórico en que se desarrolla, "la inteligencia, en efecto, cuenta en cada caso, con determinadas posibilidades teóricas, que se constituyen como resultado de una marcha histórica y que representan el sustrato desde el cual se piensa" ${ }^{38}$. Esto significa tomar en cuenta que dentro de cada lectura de fe existen determinaciones históricas precisas, es decir, condicionamientos que no siempre son solamente teóricos, sino presentes en determinadas condiciones históricas.

Segundo: el conocer humano hace referencias explicitas a la realidad humana, es decir, no solo cumple una función de contemplación, sino también práxica que se configura desde determinadas prácticas sociales, estas

37 Ellacuría, "Hacia una fundamentación...", 209-10.

38 Ellacuría, "Hacia una fundamentación...", 209. 
fuerzas son las que permiten e influyen en la producción intelectual y en la incidencia de determinados intereses predominantes. Esta dimensión social del conocimiento incide, claramente, en la hermenéutica teológica, la cual, por medio del uso de un análisis crítico, debe ir más allá de las ideologizaciones. Por ello, debe darse desde la teología latinoamericana un desenmascaramiento de la producción teológica.

Tercero: este elemento activo de la inteligencia la vincula directamente con la praxis, pues "el conocer humano, según el tipo que sea y con una referencia, necesita la praxis no solo para su comprobación científica, sino también para ponerse en contacto con la fuente de muchos de sus contenidos" 39 . Es decir, el conocimiento necesita una referencia a la realidad como principio y fundamento de su actividad. Si se toma en cuenta la dinamicidad de la realidad, entonces dicha función cognoscitiva no puede ser estática o pasiva; la función intelectual debe estar inserta, de manera activa, en la realidad, pues "la actividad de la inteligencia humana está condicionada por el mundo histórico en el que se da. De aquí la necesidad de conocer o indagar las condiciones históricas en las que se da un conocimiento, teoría, propuesta de interpretación teológica" ${ }^{40}$.

39 Ellacuría, "Hacia una fundamentación...", 211.

40 Mardones, "La historización...", 201.
De esta manera, para Ellacuría, el método se considera como un momento teórico de la praxis, pero iluminado por las necesidades de una Iglesia comprometida con la transformación de las situaciones injustas presentes en la sociedad, por lo tanto, "hay que situarse en el mismo lugar histórico donde la fe es captada plenamente y donde hay mayores posibilidades de autenticidad" ${ }^{41}$.

\subsubsection{El método de la historización de los conceptos}

Los presupuestos anteriores permiten comprender que la historización es un recurso utilizado por Ellacuría a lo largo de toda su obra, como un criterio que se alimenta de la teoría de la inteligencia zubiriana, la cual se relaciona, de manera directa, con la historia y la realidad. Además, tiene como propósitos fundamentales superar el deseo de universalidad presente en la teología tradicional, para abrirse paso en la construcción de conceptos elaborados desde la situación histórica, particularmente de las mayorías empobrecidas del continente. Otro de sus fines es la desideologización, comprendida como la falsedad que encubre la realidad, presente en no pocas teorías teológicas, las cuales se han prestado a lo largo de la historia a intereses particulares.

41 Ellacuría, "El método...", 233. 
Como punto de partida, es necesario expresar que para Ellacuría un concepto histórico se comprende en una clara oposición a lo abstracto y universal, "el concepto histórico por referirse inmediatamente a realidades históricas, a realidades cambiantes que dependen de la situación estructural y coyuntural en la cual se dan, cobra significado distinto, según el momento del proceso y según el contexto en el que se da" $"$.

Esto implica no asumirlos de manera unívoca, pues es imposible partir de contenidos dogmáticos previamente establecidos, por lo que hay que asimilar que su verdad se encuentra en proceso de realización y se mide en sus resultados concretos; se trata de comprender que son contenidos operativos y dinámicos, abiertos a cada situación histórica, pero que no pierden su sentido esencial. Por tanto, "mostrar lo que van dando de sí en una determinada realidad ciertos conceptos, es lo que se entiende aquí por historización" ${ }^{43}$.

Desde el ámbito filosófico, Ellacuría ofrece algunos criterios del método de historización de los conceptos, en un primer momento se esquematizan estos planteamientos, para luego dar paso a su análisis y aporte a la reflexión teológica actual.

42 Ellacuría, "La historización...", 590.

43 Ellacuría, "La historización...", 591.
En su curso Ideología $e$ inteligencia, el autor visualiza los siguientes aspectos ${ }^{44}$ :

a. El principio fundamental de la historización es la verificación histórica, la cual permite comprobar, si lo que se ha dicho en abstracto se cumple en la realidad, pues algo carece de verdad, si se evidencia que produce un efecto contrario a lo que predica.

b. Posteriormente, afirma que la puesta en marcha de un concepto en una praxis histórica concreta permitirá dilucidar lo que ofrece o esconde.

c. Cuando un concepto ha sido invalidado por su puesta en marcha en la historia, no hay espacio a los argumentos que comprendan dicha invalidación como un acto aislado, esto si la invalidación se ha realizado en una sociedad $\mathrm{y}$ tiempo determinado.

d. La historización implica sobrepasar tres niveles claves: el de la intencionalidad, pues los principios ideológicos poseen efectos reales y rigen comportamientos reales; el de los fenómenos, pues en estos la realidad se manifiesta solamente de manera parcial y

44 Ellacuría, "Ideología e inteligencia", 375-76. 
el de la pseudoconcreción, esto significa comprender que todas las realidades se encuentran conectadas entre sí.

e. Desde la historización, las nociones abstractas que funcionan como rectoras de la praxis poseen dos estratos: los que la propulsan y esperan su éxito y otros de enmascaramiento como elemento encubridor.

f. El mensaje ideologizado no se rechaza en su totalidad, pues puede poseer algunos elementos de verdad; la historización lo que muestra, a través del vínculo con la praxis, es el modo real de convertir en realidad lo que se plantea a manera de ideal.

Como puede verse, Ellacuría no analiza los conceptos separados de la realidad, ni de modo autosuficiente, "sino que los está entendiendo siempre en respectividad a la praxis humana, o más propiamente como momentos de la praxis" $"$. En su propuesta, más que el deseo de ofrecer una metodología rígida, lo que subyace es una clara intención de eliminar todo tipo de mistificación y formalidad abstracta, pues "La historización consiste en ver cómo se está realizando en una circunstancia dada, lo que se afirma abstractamente [...] consiste, en segundo lugar, en la

45 Juan A. Senent, Ellacuría y los derechos humanos (Bilbao: Desclée de Brouwer, 1998), 153. posición de aquellas condiciones sin las cuales no se puede dar una realización efectiva" ${ }^{46}$.

En síntesis, este método es una hermenéutica que va más allá de un simple recorrido histórico de los conceptos; como lo afirma Héctor Samour, se trata de desarrollar una aproximación metodológica a la historia:

Entendida en su carácter formal de praxis para dilucidar críticamente el sentido expresado en las interpretaciones y en los discursos que legitiman las relaciones de poder y dominación, desenmascarando su pretendida universalidad y poniendo en evidencia las condiciones y los intereses reales que las sustentan" ${ }^{\prime 4}$.

Aplicando esta reflexión filosófica de Ellacuría a los conceptos de naturaleza teológica, pueden enumerarse los siguientes criterios de análisis. El método de historización es un intento por descubrir el nivel de ideologización presente en los conceptos, es decir, desenmascarar la carga ideológica que muchas veces poseen, sus intereses o incluso manipulaciones ocultas. En el discurso teológico es necesario

46 Ignacio Ellacuría, "Historización del bien común $\mathrm{y}$ de los derechos humanos en una sociedad dividida", en Escritos filosóficos III (E1 Salvador: UCA Editores, 2001), 217.

47 Héctor Samour, "La función liberadora de la filosofía y el método de historización de los conceptos en Ignacio Ellacuría”, en Ignacio Ellacuría, intelectual, filósofo y teólogo (Madrid: ADGN Libros, 2012), 110. 
reconocer, de la mano de Ellacuría, que "muchas veces tras la normativa absoluta y abstracta, se da el encubrimiento ideologizado e interesado, que defiende lo ya adquirido, sin discutir el modo de esa adquisición" ${ }^{48}$. Se construye una normativa abstracta, ajena a la realidad y circunstancias históricas, carente de significado para los sujetos participantes de las comunidades religiosas, normas y cánones se posicionan por encima de la vivencia y experiencia cotidiana.

Ellacuría expresó que el ser humano utiliza su inteligencia para sobrevivir, por lo que el conocimiento no es objetivo, sino que se encuentra influenciado por todo un conflicto de intereses. Esto aplica también para la teología, pues "un ejercicio falsificado de la razón puede aparentar ser científico, cuando en realidad es un vehículo de dominación"49, al emitir formulaciones y principios orientados más por el deseo de poder que por el crecimiento espiritual. Significa que la teología tampoco es neutra, la defensa de la ortodoxia puede responder a temores concretos en torno al miedo de perder la autoridad, por parte de las jerarquías, la desideologización invita a descubrir cuál es la ideología dominante y cómo se estructura en cada momento

48 Ignacio Ellacuría, "Historización de los derechos humanos desde los pueblos oprimidos y las mayorías populares", en Escritos filosóficos III (El Salvador: UCA Editores, 2001), 435.

49 Ellacuría, "La historización...", 589. histórico; es necesario reconocer que las distintas teologías no se encuentran exentas de esta carga ideológica y Ellacuría ofrece las pistas para analizar, de manera crítica, los presupuestos teológicos para desmitificarlos y descubrir sus principales falseamientos.

Finalmente, la historización invita a confrontar los conceptos con la realidad, para conocer su veracidad histórica. En la actualidad es imperiosa la necesidad de que los principios teológicos se encuentren encarnados en las situaciones concretas, no solo para facilitar su comprensión, sino que su construcción misma debe realizarse desde coordenadas específicas. Historizar los conceptos no es un elemento único de la teología de la liberación elaborada por Ellacuría, es un elemento que debe estar presente en todo proceso de reflexión teológico contemporáneo.

\section{Conclusiones}

El análisis de la historización como hilo conductor del pensamiento de Ignacio Ellacuría, permite formular las siguientes conclusiones:

La base zubiriana del pensamiento de Ellacuría le permite llevar los planteamientos teológicos a una dimensión novedosa, en la cual la teología tradicional se encuentra en deuda; la concepción de la inteligencia como sentiente y el valor metafísico atribuido a la historia y la realidad conllevan 
un pensamiento teológico en diálogo directo con la realidad histórica. Este aspecto resulta difícil de encontrar en una teología clásica sustentada en una metafísica medieval, incapaz de dialogar con sus entornos y elaborada desde rígidos esquemas occidentales.

La teología tradicional se encuentra en deuda con el continente latinoamericano, su deseo de universalismo la ha llevado a formulaciones abstractas y ahistóricas, pensamientos como el de Ignacio Ellacuría ofrecen los criterios suficientes para la construcción de un pensamiento teológico creativo, abierto a los retos y circunstancias de una realidad en la que debe encarnarse de manera más profunda.

La historización de los conceptos permite descubrir el grado de ideologización presente en la teología, en la cual muchas nociones han sido elaboradas a partir de intereses concretos. Ellacuría ofrece las bases para realizar una desmitificación del pensamiento teológico, para purificarlo de las cargas ideologizantes que alejan el discurso religioso de las experiencias religiosas cotidianas, particularmente de las vivencias, retos y dificultades experimentados por las mayorías más desfavorecidas del continente.

A partir de las tesis de Ellacuría sobre la necesidad de historizar la teología, las iglesias y sus diversas estructuras jerárquicas deben cuestionarse sobre cómo conciben los conceptos fundamentales de sus discursos. Hablar de revelación, salvación y reino debe implicar, en definitiva, una verificación histórica que abra las puertas a un proceso integral de liberación y que permita el cuestionamiento y reformulación de muchos de sus argumentos y tesis fundamentales.

Finalmente, el esfuerzo de Ellacuría es digno de encomio, desde su perspectiva, lo importante no es la aplicación de un método rígido y estático o el cumplimiento de objetivos pastorales, la clave radica en el proceso mismo, el cual genera liberación y permite la construcción del reino. En términos de Juan J. Tamayo: "Ellacuría historizó y humanizó la imagen de Dios, liberándola del teísmo político que utiliza el nombre de Dios hasta su manipulación en función de intereses espurios, sin por ello negar su trascendencia" ${ }^{50}$.

\section{Bibliografía}

Domínguez, Manuel. "Aproximaciones al concepto de praxis en Ignacio Ellacuría" Revista Universitas Philosophica, 21, 41-57. 1993.

Ellacuría, Ignacio. Filosofia de la realidad histórica, Madrid: Editorial TrottaFundación X. Zubiri. 1991.

50 Juan J. Tamayo, "Ignacio Ellacuría: Profetismo, utopía y derechos humanos", en Ignacio Ellacuría, intelectual, filósofo y teólogo (Madrid: ADGN Libros, 2012), 88. 
Ellacuría, Ignacio. La teología como momento ideológico de la praxis eclesial. En Escritos teológicos I. El Salvador: UCA Editores.163-186. 2000.

Ellacuría, Ignacio. El desafío cristiano de la teología de la liberación. En Escritos teológicos I. El Salvador: UCA Editores. 19-36. 2000.

Ellacuría, Ignacio. El método en la teología latinoamericana. En Escritos teológicos I. El Salvador: UCA Editores. 219-34. 2000.

Ellacuría, Ignacio. Relación teoría y praxis en la teología de la liberación. En Escritos teológicos I. El Salvador: UCA Editores. 235-48. 2000.

Ellacuría, Ignacio. Tesis sobre la posibilidad, necesidad y sentido de una teología latinoamericana. El Salvador: UCA Editores. 271-302. 2000.

Ellacuría, Ignacio. Utopía y profetismo, en Mysterium Liberationis: Conceptos fundamentales de la teología de la liberación, dirigido por Ignacio Ellacuría y Jon Sobrino. El Salvador: UCA Editores. 393-442. 2000.

Ellacuría, Ignacio. ¿Filosofía para qué? En Escritos filosóficos III (El Salvador: UCA Editores, 115-132. 2001.

Ellacuría, Ignacio. Historización del bien común y los derechos humanos en una sociedad dividida. En Escritos filosóficos III. El Salvador: UCA Editores. 207-226. 2001.
Ellacuría, Ignacio. Historización de los derechos humanos desde los pueblos oprimidos y las mayorías populares. En Escritos filosóficos III. El Salvador: UCA Editores. 433-446. 2001.

Ellacuría, Ignacio. Superación del reduccionismo idealista. En Escritos filosóficos III. El Salvador: UCA Editores. 404-30. 2001.

Ellacuría, Ignacio. El objeto de la filosofía. En Escritos políticos I. El Salvador: UCA Editores. 63-92. 2005.

Ellacuría, Ignacio. Función liberadora de la filosofía. En Escritos políticos I. El Salvador: UCA Editores. 93122. 2005.

Ellacuría, Ignacio. La historización del concepto de propiedad privada como principio de desideologización. En Escritos políticos I. El Salvador: UCA Editores. 587-628. 2005.

Ellacuría, Ignacio. La historicidad del hombre en Xavier Zubiri. En Escritos filosóficos II. El Salvador: UCA Editores. 199-284. 2007.

Ellacuría, Ignacio. El esquema general de la antropología zubiriana. En Escritos filosóficos II. El Salvador: UCA Editores. 285-364. 2007.

Ellacuría, Ignacio. Principialidad de la esencia en Xavier Zubiri. En Escritos filosóficos II. El Salvador: UCA Editores. 149-76. 2007. 
Ellacuría, Ignacio. Ideología e inteligencia, en Cursos universitarios. El Salvador: UCA Editores.327-78. 2009.

Mardones, José M. La historización de los conceptos teológicos, en La pasión por la libertad. Homenaje a Ignacio Ellacuría. Navarra: Editorial Verbo Divino.189-212. 1994.

Samour, Héctor. Voluntad de liberación. La filosofía de Ignacio Ellacuría. El Salvador: UCA Editores. 2006.

Samour, Héctor. La función liberadora de la filosofía y el método de historización de los conceptos en Ignacio Ellacuría. En Ignacio Ellacuría, intelectual, filósofo y teólogo. Madrid: ADGN Libros. 89-116. 2012.

Senent, Juan. A. Ellacuría y los derechos humanos. Bilbao: Desclée de Brouwer. 1998.

Tamayo, Juan J. Ignacio Ellacuría: Profetismo, utopía y derechos humanos. En Ignacio Ellacuría, intelectual, filósofo y teólogo. Madrid: ADGN Libros. 67-88. 2012.

Zubiri, Xavier. Inteligencia sentiente. Inteligencia y realidad, Madrid: Alianza Editorial- Fundación X, Zubiri. 2011. 
